\title{
Article
}

\section{Elite football player engagement with performance analysis}

Wright, C., Carling, C., Lawlor, C., and Collins, D.

Available at http://clok.uclan.ac.uk/15896/

Wright, C., Carling, C. ORCID: 0000-0002-7456-3493, Lawlor, C., and Collins, D. ORCID: 0000-0002-7601-0454 (2016) Elite football player engagement with performance analysis. International Journal of Performance Analysis in Sport, 16 (3). pp. 1007-1032. ISSN 2474-8668

It is advisable to refer to the publisher's version if you intend to cite from the work.

For more information about UCLan's research in this area go to

http://www.uclan.ac.uk/researchgroups/ and search for < name of research Group>.

For information about Research generally at UCLan please go to http://www.uclan.ac.uk/research/

All outputs in CLoK are protected by Intellectual Property Rights law, including Copyright law. Copyright, IPR and Moral Rights for the works on this site are retained by the individual authors and/or other copyright owners. Terms and conditions for use of this material are defined in the policies page.

\section{CLoK}

Central Lancashire online Knowledge www.clok.uclan.ac.uk

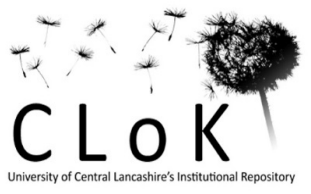


This is a pre-proof corrected manuscript, as accepted for publication, of an article published by Cardiff Metropolitan University in the Journal of Performance Analysis in Sport on $1^{\text {st }}$ December 2016, available online:

http://www.ingentaconnect.com/content/uwic/ujpa/2016/00000016/00000003/art00022

\section{PLEASE REFER TO FINAL VERSION FOR CITING PURPOSES}

Title: Elite football player engagement with performance analysis

International Journal of Performance Analysis of Sport:

Craig Wright ${ }^{1}$, Chris Carling ${ }^{1,2}$, Craig Lawlor ${ }^{3}$, David Collins ${ }^{1}$

Institutions:

${ }^{1}$ Institute of Coaching and Performance, University of Central Lancashire, UK

${ }^{2}$ LOSC Lille Métropole Football Club, Domain de Luchin, Camphin-en-Pévèle, 59780, France

${ }^{3}$ Blackburn Rovers Football Club, UK. 


\begin{abstract}
:
Despite the wide spread employment of Performance Analysis (PA) within the football coaching process to enhance augmented feedback, until recently little consideration has been given to the context in which PA delivery takes place at elite levels and subsequently impacts on players receiving such information. The aim of this investigation was to explore players' preferred engagement with the PA approach. Comparisons were also drawn between Senior and Academy players. Method: A two phase methodology was employed. 48 male footballers from three English Championship football clubs completed an online questionnaire. Following this 22 players were selected using an opportunistic sample to complete a semi-structured interview. Results/ Discussion: In total, the hierarchical content analysis identified 26 higher order themes and 103 lower order themes. Three key themes emerged and were explored within the discussion: (1) the level of debate and player interaction differed greatly during video feedback sessions, (2) the use of video analysis is central to player self-reflection but the level of engagement with self-reflection varied across players, (3) the majority of players preferred some delay (between 24 and 48 hours) before receiving video feedback. Chi-square statistical analysis identified no meaningful differences in the responses between Senior and Academy players and as a result only descriptive findings were reported. These factors have provided further insight into the practical contexts in which PA is used and perceived by elite players. The most eminent findings have potential implications for coach and analyst education. Further contemplation should be given to the level of interaction during PA feedback as a result of the willingness and ability of a coach to engage a player in discussion regarding their performance and PA use within the player self-reflection process.
\end{abstract}

\title{
Keywords:
}

Match analysis, Video feedback, Player perceptions, Qualitative approaches, Hierarchical content analysis. 


\subsection{Introduction:}

Augmented feedback is a broad concept and its many forms have been extensively reviewed (cf Hodges and Franks 2008). Augmented feedback has also been identified as an integral part of the delivery of the performance analysis (PA thereafter) process and approaches (O'Donoghue, 2010). Despite this there seems to be a gap between the research surrounding motor learning, feedback approaches (Hodges and Franks, 2008) and how this might translate to the delivery of PA information. Therefore one would suggest that the application of PA, within the feedback process specifically, hinges upon the ability of the coach to deliver information correctly and efficiently whilst taking into account a number of contexts, interpersonal and social factors (Potrac et al., 2002; Groom et al., 2012; Booroff et al., 2015).

An important question that is key to the present study is the extent to which coaches are engaging players during video sessions and the impact these sessions have on a player's learning and subsequent performance. Traditionally sports coaches have made the assumption that winning is based on the foundations of technical and tactical superiority (Denison, 2010; Grecic and Collins, 2013). Such a mechanistic approach has been further perpetuated by the role of sports science in supplementing the coaching process (Gilbert and Trudel, 2005; Reilly and Williams, 2005). Thus, mechanistic approaches have been adopted by some of the world's most influential coaches (Curzon-Hobson et al., 2003; Williams and Hodges, 2005; Denison, 2010). Clearly, PA has played a role in propagating such an epistemological approach but recent evidence from player development has highlighted a more athlete centred, holistic approach as being conducive to fostering elite players (Potrac et al., 2000; Jones and Wallace, 2005; Allen and Hodge, 2006; Ollis and Sproule, 2007; Abraham and Collins, 2011; Grecic and Collins, 2013). 
Notably such coaching approaches are in direct contradiction to a more traditional instructor based, learn-do philosophy, often associated with elite football coaches' approaches (Williams and Hodges, 2005; Harvey et al., 2010; Partington and Cushion 2013). Subsequently a key concept which was considered in this investigation is to what extent such changes in approaches are reflected in the use of PA by the coach during feedback and debriefing sessions, if at all? Are sessions perceived by players as a one way method to deliver technical instruction and information as highlighted by Potrac, Jones and Amour (2002) or a two way dialogue regarding performance?

A second key concept central to this paper is the use of PA to supplement reflective practice. Reflective practice has become a central concept within coaching literature and coach education over the last two decades (Cassidy et al., 2004; Cassidy et al., 2006). Many coaches have been encouraged to embrace approaches which facilitate player selfanalysis, self-reflection and which develop players' own decision making capabilities, many of which lend themselves to the use of PA tools and approaches (Wright et al., 2012; Grecic and Collins 2013; Wright et al., 2013). The applications of PA approaches have become important aspects of the self-analysis and reflective logs of Academy players as outlined by the Premier League Elite Player Performance Plan (EPPP - Youth Development Rules, 2012), and are becoming widely employed in football academies. Such processes might encourage more independent learners when supplemented with a coach's input. However, the extent to which such opportunities are facilitated via the means of PA within professional football settings remains unexplored.

It has been well documented that the coaching process has often been oversimplified. Recent empirical work has attempted to highlight the process as something which is not merely the delivery of instructional information but is a dynamic social activity (Jones, 
2000; Jones, Armour, Potrac, 2002) and therefore alternative research approaches have been suggested. Glazier (2010) and Mackenzie and Cushion (2012) provided additional support and state that a more action-based, case-study type approach is required to investigate questions specific to performance. Nelson et al. (2011) echo this point suggesting that more naturalistic and qualitative methods such as case studies, interviews and mixed method approaches may be beneficial in developing new knowledge and understanding in order to further explore the use of PA (Nelson and Potrac, 2014; Huggan et al., 2014; Booroff et al., 2015;). In order to best address this specific research problem a two phase approach was employed. Phase one would collect survey information regarding the experiences of football players receiving performance analysis feedback. Sequentially this was followed with phase two which would build upon the findings from phase one by employing qualitative techniques to explore the personal experiences of players within one to one interviews, thus providing further interpretation of the exposure of the players to PA feedback.

The overall aim of this investigation was to explore the preferred engagement of players with the PA approach. The first objective was to identify player perceptions of the timing, frequency, content, duration and the environment in which players receive PA feedback sessions. The second objective was to determine how 'involved' players feel they are in the PA process.

\subsection{Method}


There are a number of clear strengths for considering this discipline from an alternative Ontological and Epistemological paradigm. By grounding the research within a Constructivist and Interpretivist view, this would undoubtedly provide an alternative perspective of the current research topic, strong evidence of this has been seen in the most current research (Nelson et al., 2011; Huggan et al., 2014; Booroff et al., 2015). The key aim of this paper is the interpretation of how players responded to PA interventions. A two-phase approach was employed using preliminary statistics followed by interviews. The motivation for the statistics are still interpretive and grounded in that the brief use of statistics was the best way to manage the subjects and data at the time (Glaser and Strauss, 2012). By employing a two-phase approach the preliminary data collected via survey methods provided background to an area which, until only recently, had been the subject of limited investigation. This provided some much needed direction when considering questions to be explored within the subsequent interview. It was anticipated that the qualitative research could be used to facilitate the interpretation of the relationships between variables identified in the initial quantitative data collection. It was also anticipated that this should help bridge the gulf between macro and micro levels of research findings (Niglas, 2000; Smith, 2010, Glaser and Strauss, 2012). The research methods selected should be responsive to the particular research problem or question (Casebeer and Verhoef, 1997, Smith, 2010), employing a two phase approach also aligns with a pragmatic research philosophy. The aims of the research method were clearly guided by the applied problems the research had encountered and as a result it was anticipated that the subsequent generation of applied research should 'make a difference to the individuals or groups that it examines' (Giacobbi et al., 2005; Corbin and Strauss, 2008). A central concept to this study relates to how and why players engage with 
different approaches within competitive football clubs. Pragmatic research philosophy has highlighted the importance of providing an interpretation of the actions and activities associated with practitioner's everyday practices (Stringer, 2007), thus the research questions appear to have aligned with a pragmatic research philosophy. Pragmatic research philosophy has also identified the importance of real world processes and functions and is less concerned with a definitive representation of reality and realities (Cruickshank et al., 2013; Cruickshank et al., 2014).

\subsection{Two Phase Approach}

\subsubsection{Participants}

Altogether 48 male footballers from three different English Championship football clubs completed an online questionnaire. Players were full time Academy (Under 18's, n=31) or Senior (development/ $1^{\text {st }}$ team, $n=17$ ) players. Out of these 48 players, 22 were selected using opportunistic sampling to complete a semi-structured interview (based on player availability within the player training week and their willingness to take part in the study). Of the 22 players which participated in the interviews 12 were full time Academy (Under 18 's) and 8 were Senior (development $/ 1^{\text {st }}$ team) players. Following the host institute granting ethical approval, all participants were provided with information relating to the nature of the study and completed a written informed consent form prior to each interview.

\subsubsection{Design}


All 48 players were initially asked to fill in online questionnaires at http://www.surveymonkey.com and 22 players were subsequently selected to take part in a semi-structured interview which consisted of 14 open-ended questions (available on request from the lead author). During this process the lead author acted as an 'active listener' in an attempt to assist the players in describing their own experiences and preferences in their own words (Smith and Sparkes, 2005). It was hoped that the players would give open, honest and more in depth answers due to the main author's previous rapport with the players while the analyst from each club also assisted in the data collection process (Athens, 1984). The interviews were recorded using a recording device in order to be later transcribed and each interview lasted between 22 and 35 minutes, in total 21,586 words were transcribed and analysed in Nvivo. The research design was considered appropriate as Francis and Jones (2014) recently suggested that a quantitative questionnaire using a Likert scale to evaluate player perceptions should be used alongside semi-structured interviews to gain an insight into personal views and opinions of PA.

\subsection{Data analysis and trustworthiness: Questionnaire}

The content for the questionnaire and interviews was established via extensive observation of PA feedback to players within 3 football clubs and informal discussion with the players, coaches and analysts. The research team and the 3 lead analysts working within the football clubs involved with the study engaged in a critical discussion regarding player exposure to PA within their clubs. The discussions focused on the practical environment in which PA was delivered and player engagement with these processes. The discussion was also directed by some key preceding literature relating to this topic (Groom and Cushion, 2004; Groom et al., 2011; Francis and Jones, 2014). Within the discussion between the research team and analysts specific consideration was given to the 
'Contextual Factors' identified by Groom et al., (2011) relating to Recipient Qualities. Particular attention was paid to the following factors: Psychology of the recipients and Reflective players (Groom et al., 2011). Following these professional discussions a number of potential themes were established and a bank of potential questions were formed which was developed into the initial questionnaire. A final set of questions were piloted on a group of 5 players, 4 analysts and 5 academics who had interest in the topic area (the results from the pilot testing was not included in the final data collection). From the pilot questions, feedback was provided and the most appropriate questions were selected and then refined based on the feedback provided by the participants from the pilot testing. These questions were then refined during two further meetings between the lead author and the lead analysts from the 3 clubs. Once a set of final questions were established, they were provided to the 3 lead analysts within the clubs to conduct the questionnaire with their players at the most appropriate time for maximum response rate. The reliability and validity of the questionnaire content and structure was also established from feedback via preceding research by the current authors (Wright et al., 2012; Wright et al., 2013). Once the players had completed the questionnaire, responses were immediately available at www.surveymonkey.com and were subsequently exported for analysis in Microsoft Excel and SPSS version 20. These findings were predominantly used to inform the subsequent interviews, with only the key findings being reported in the results / discussion section. Data derived from the questionnaire was collated and coded as frequency counts. Likert scale items were coded as $5-1$ to represent the categories of the participants' preferred responses, these were represented as percentages of total number of responses and the number of counts observed from the two groups representing Academy and Senior players. The reader is referred to Tables 1 and 2. 
Further analysis was then explored using chi-square, which was implemented due to the type of data being nominal (groups, Academy and Senior players) and categorical in terms of player preferences relating to the delivery of video feedback. Nonparametric tests were also deemed appropriate because of the type of data (non-ratio) and the unequal and small sample size, resulting in non-normal distribution of the data. However no significant differences were observed between groups using Chi-square analysis, thus it was deemed not relevant to report these findings. The basic descriptive statistics were still included within this paper because these were important in providing context to the subsequent qualitative interviews with the Academy and Senior groups of players.

\subsection{Data analysis and trustworthiness: Interview data collection.}

Analysis was carried out on the interview transcripts using hierarchal content analysis in accordance with Pain and Harwood (2004); Harwood, Drew and Knight, (2010); Sparkes and Smith (2014). The researcher (first-author) immersed himself in the raw data to become familiar with all aspects of the audio interviews, transcripts and memos. Significant statements relating to player engagement with PA were identified; notes were transformed into concise phrases to produce a set of concepts representative of player

responses. Raw data themes were used to establish code in QSR Nvivo (Qualitative Solution Research 2002, Version 10, www.qsrinternational.com) and all interview transcriptions were coded following an inductive approach in Nvivo using these established codes. Connections between themes were identified to cluster raw data themes into meaningful categories which fitted together. Nvivo was then used to code and establish higher order themes which represented the themes contained within each category. At this point clusters of data were crossed checked with the initial transcribed 
material to ensure these remained consistent with the actual wording of the participants. An investigator who was not present during the data collection, but experienced in qualitative research, reviewed the analysis to complete inter-reliability checks. Two researchers carried out consensus and validation checks which involved the coding of 4 interview transcripts from player interviews (Martindale and Nash, 2012) to establish the appropriateness of the higher and lower order codes established in Nvivo. Following coding of all interview data an initial draft of the hierarchical content analysis tables was competed. From this it was established that inter-related agreement amongst researchers was found to be $84 \%$ for the higher order categories and $81 \%$ for the lower order categories. These results are within the previously reported values $(>80 \%$, in Keegan et al., 2009; Keegan et al., 2014). At this point the appropriateness of higher and lower order codes was critically reviewed by the research team. From this the hierarchical content analysis was finalised which incorporated the higher and lower-order themes that described the participants' views (Pain and Harwood, 2004; MacNamara et al., 2010). Several steps were taken to establish trustworthiness, as outlined by Lincoln et al. (2011); Martindale and Nash (2012). To maximise the levels of open-ended responses probes were used only to provide additional clarification of points made by a player and to identify examples from the participant's practice when required. In order to reduce any personal bias during the collection and interpretation, the lead interviewer bracketed their own views as much as possible (Sparkes and Smith, 2014). As part of the piloting interview the lead researcher held interviews with a member of the research team to discuss potential bias which the lead researcher might have in terms of the PA in elite football, thus attempting to minimise such bias during subsequent interviews. Two researchers carried out reliability and consensus validation checks, as described above, in 
accordance with Martindale and Nash (2012). The results consensus checks were discussed by the researchers, who acted to finalise details and confirm the level of agreement and consistency of the merging themes and categories. Peer debriefing was completed throughout the analysis of the results between the research team and the 3 lead analysts from the football clubs, which was key in the research team establishing consensus of the findings and a key stage in further establishing credibility, dependability and transferability of the findings (Shenton, 2004; Smith, 2010). These debriefings were key in providing specific insight to player response relating to the specific context of each football club's daily practices relating to PA. Finally, based upon the recommendations of Lincoln and Guba (1986), member checks were conducted whereby a summary of the results coupled with the conceptual framework was sent to a selection of the players so they could verify accuracy and provide feedback on their interpretation. This allowed for confirmation of the quotation or conversation with the researchers and the interviewees (Gutkind, 1997). Further consultation with the players confirmed the accuracy of the results and appropriateness of the framework. In total 26 higher order themes and 103 lower order themes emerged from the data.

\subsection{Results: player survey data (Refer to Table 1 and Table 2)}

Results showed that the vast majority of players were of the opinion that feedback sessions should be no longer than 30 minutes in duration, with $54 \%$ of players suggesting that sessions should last 11-20 minutes and 35\% suggesting that they should be 21-30 minutes.

By referring to Table 1 there generally seems to be parity between the actual duration of feedback sessions and what players would perceive as the optimal duration of such sessions. 
With regards to post-match feedback, $93 \%$ of players stated that they would like to receive feedback one or two days after the game with just over half $(58 \%)$ preferring video feedback two days after a game. A total of $52 \%$ of academy players and $24 \%$ of senior players identified that feedback was mostly positive while $39 \%$ (Academy players) and $70 \%$ (Senior players) identified that there was a balance between positive and negative feedback.

Table 1: The pre-match feedback process actual and preferred duration of video feedback sessions

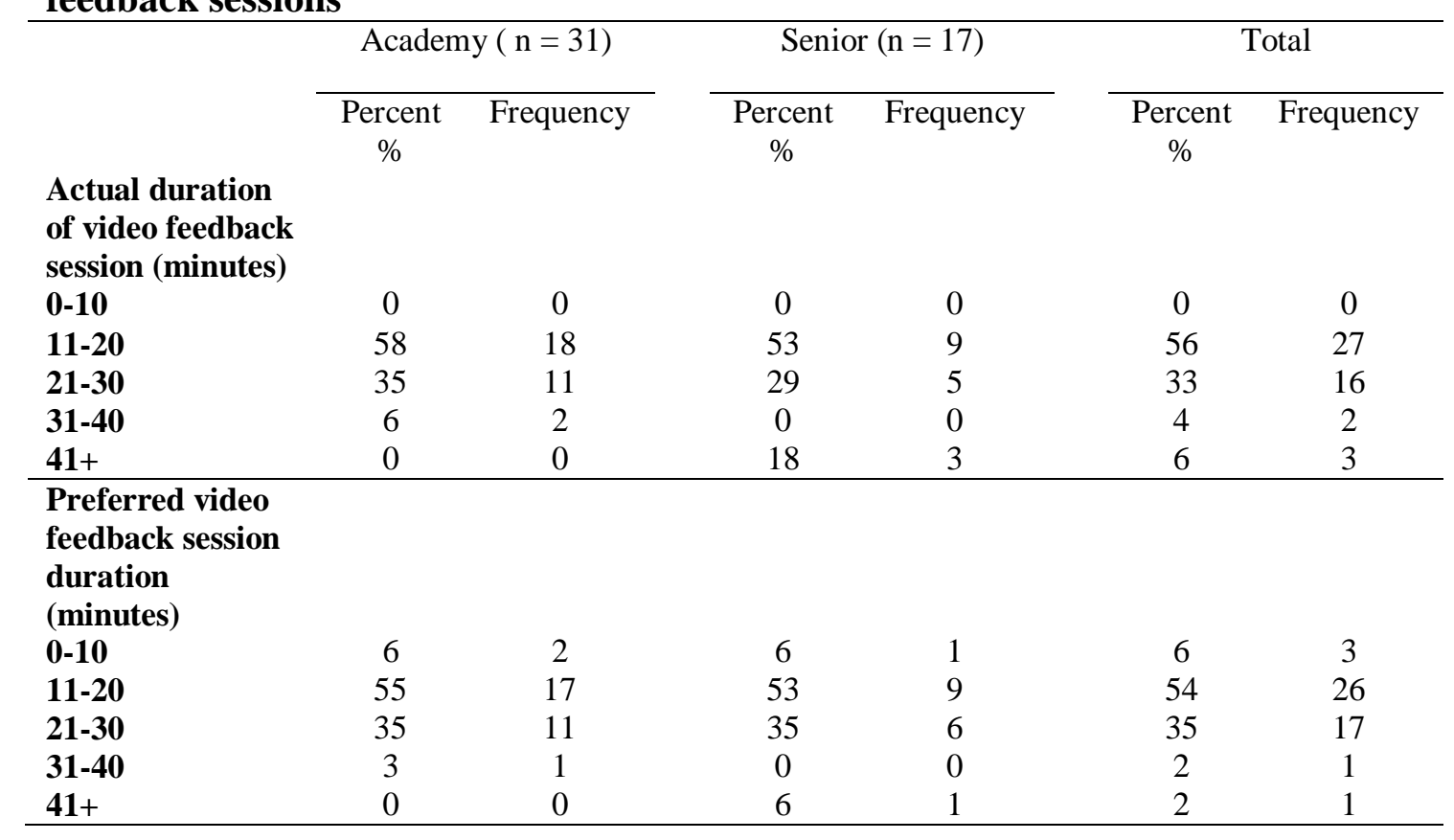




\begin{tabular}{|c|c|c|c|c|c|c|}
\hline \multirow[b]{3}{*}{$\begin{array}{l}\text { Type of } \\
\text { feedback } \\
\text { received }\end{array}$} & \multicolumn{2}{|c|}{ Academy $(\mathrm{n}=31)$} & \multicolumn{2}{|c|}{ Senior $(n=17)$} & \multicolumn{2}{|c|}{ Total } \\
\hline & $\begin{array}{c}\text { Percent } \\
\%\end{array}$ & Frequency & $\begin{array}{c}\text { Percent } \\
\%\end{array}$ & Frequency & $\begin{array}{c}\text { Percent } \\
\%\end{array}$ & Frequency \\
\hline & & & & & & \\
\hline Always Positive & 6 & 2 & 0 & 0 & 4 & 2 \\
\hline Mostly Positive & 52 & 16 & 24 & 4 & 42 & 20 \\
\hline $\begin{array}{l}\text { Balance of } \\
\text { Positive \& } \\
\text { Negative }\end{array}$ & 39 & 12 & 70 & 12 & 50 & 24 \\
\hline Mostly Negative & 0 & 0 & 6 & 1 & 2 & 1 \\
\hline Always Negative & 3 & 1 & 0 & 0 & 2 & 1 \\
\hline $\begin{array}{l}\text { Preferred } \\
\text { timing of } \\
\text { feedback session }\end{array}$ & & & & & & \\
\hline Same Day & 6 & 2 & 0 & 0 & 4 & 2 \\
\hline Next Day & 32 & 10 & 41 & 7 & 35 & 17 \\
\hline 2 Days & 58 & 18 & 59 & 10 & 58 & 28 \\
\hline 3 Days & 3 & 1 & 0 & 0 & 2 & 1 \\
\hline 4 Days & 0 & 0 & 0 & 0 & 0 & 0 \\
\hline
\end{tabular}

\subsection{Qualitative findings from player interviews}

The hierarchical content analysis illustrating the player perceptions are presented in Tables 3 to 7 (refer to the end of the paper).

\subsection{Results and Discussion}

Through the systematic analysis of player perception of PA, three important features emerged which were consistent across all clubs and standards of play (1) the level of debate and player interaction differed greatly during video feedback sessions, (2) the use of video analysis was central to player self-reflection but the level of engagement with self-reflection varied across players, (3) The majority of players preferred some delay before receiving video feedback. 


\subsection{Duration and level of interaction during PA feedback sessions}

The findings from the survey identified that $56 \%$ of players were exposed to video feedback sessions of a duration of 11-20 minutes, while 33\% experienced sessions 2130 minutes in duration. The findings from Table 1 are of interest because they appear to differ from the findings of Groom and Cushion (2005) who found that with sessions lasting 30-40 minutes, 30\% of players felt that sessions were 'about right' and 70\% stated that they were 'too short'. In contrast, this study appears to agree to some extent with the preceding findings of Bunce, Flens, Neilies, (2010) who stated that individuals (non-athletes, non-sporting context) are only able to maintain focus on a task for a maximum of 20 minutes. Player responses from this study were also in agreement with Francis and Jones (2014) where players suggested that group video feedback sessions were too long, showed too many clips and suggested that sessions should contain more relevant information to highlight valuable points. Some consensus was apparent amongst the players that post-match feedback was fairly consistent in its frequency in that each team would have some sort of team review following each performance and as such PA analysis is regularly implemented within all review processes at all clubs. For all clubs the post-match sequence meant that a game would be followed by a rest day and the next day would be a team review (with the exception of when an additional midweek fixture occurs). No evidence was provided from the players suggesting that the duration of feedback sessions was directly linked to the outcome of performance. It has previously been identified that debrief could vary depending on performance outcome; 'I'd say the worse the result the longer the debriefing' (Groom and Cushion, 2005:4). Although consistency of the frequency of the sessions was adhered to, some variation in duration was reported. Some of the senior players identified that they were exposed to a 
combination of fairly short reviews but sometimes watched the entire game cut down to 'ball in play' while the coach commented over the game. Previous research has also identified the association between performance outcome and length of the debrief can have an important impact on the performer's mind set coming into a feedback session, in that 'debriefing was taken more seriously post a loss versus a win therefore influencing the athletes' focus on the process' (McArdle et al., 2010:138).

The preferred video feedback duration of players was 11-20 minutes with 54\% while $35 \%$ of players identified that 21-30 was a more suitable duration. However caution has to be given to this finding as it might simply be a reflection of what players are most familiar with. Despite these similarities and differences, a more pertinent consideration might be the level of engagement and interaction players perceived during these sessions. By referring to Table 1 there roughly seems parity between the actual duration of feedback sessions and what players would perceive as the optimal duration of such sessions, which might lead us to give further consideration to what happens in such sessions (actual feedback duration: 11-20 minutes, 56\%; 21-30 minutes, 33\%). The preceding literature has tended to solely focus on the player's preferred learning styles (Groom and Cushion, 2005; Reeves and Roberts, 2013), thus ignoring potentially important aspects. Although research has provided consistent evidence that both children and adults have preferences about how they like information to be presented to them, there has been little evidence to suggest that specific delivery in the preferred modality enhances student learning (cf McDaniel et al., 2008; Rasmussen, 2015). Only most recently has research started to support the social complexity associated with PA feedback sessions (Groom et al., 2012). Evidence has suggested that performers learn more as a result of 'engaging in social interaction within feedback sessions' (Nelson et al., 2011:9), 
however the timing for debriefing and implications for their subsequent effectiveness still remains vague (McArdle et al., 2010).

Within this study players appear to have a variety of opinions regarding their involvement in the PA process. From comments made by players across clubs at both Academy and Senior level there appears to be a large variation in the level of interaction and engagement during feedback sessions (refer to Table 3), which has not been reflected in the preceding PA related literature. A number of strong examples were provided by the players below, to support both high levels of engagement and positive debate during video sessions.

Yes, all our feedback sessions are structured in a way that promotes discussions between players and staff both in a positive way as well as negative. Club A Player 1: Development Squad Player

Yes feedback sessions are very much open so we can discuss what went right/wrong as a team. Pre-match opposition presentations are often more structured with less opportunity to contribute. Club A 1: Development Squad Player

I think it's important that we get to give our side of the story about games during the video sessions. Debate is healthy. Club A Player 2: Development Squad Player

Yeah, the coaches tell us to say what we were doing here and asking us how we could improve in that area. Club B Player 1: U21 Squad Player

But similarly some players experienced a more direct approach by the coaching staff, which could be perceived as being more directed and less engaging.

Yes we get to give our side however this is often disagreed by other players and the manager. Club A Player 3: First Team Player

Team feedback sessions are very formal and led by the assistant manager and manager, there isn't much opportunity for discussion. Club A Player 4: First Team Player

The feedback is directed by the manager and assistant manager highlighting where we went wrong and what we did well. The players don't get much chance to voice their opinions. Club A: Reserve team player

Not really, it's often a case of watch, listen, and take in. Club A Player 4: First Team Player 
A more direct, instructions-driven method of delivery is consistent with evidence provided by Potrac et al. (2002) when evaluating elite coach behaviour during training sessions. Such approaches were associated with the need for the coach to establish credibility with players by demonstrating their technical knowledge of the game (Potrac et al., 2002). This suggests that a mechanistic epistemological approach to coaching is evident in the approach of some coaches (Grecic and Collins, 2013). Clearly the duration of the session, the number of clips and the duration of clips which are shown (Alvarez and Cavanagh, 2004) will impact on the session itself, however the coach's leadership style and delivery approach will also have a major impact. Possibly an important consideration will also be the amount and effectiveness of questioning being employed during feedback sessions, if any at all. These factors might help in establishing the level of engagement, if any, during feedback sessions, which in turn might increase likelihood of retention and transfer of learning (Collins, 2012). When reviewing the comments made by players who experienced open discussion during feedback a number of additional considerations were raised (refer to Table 3). One player seemed disappointed that the open discussion experienced during post-match was not replicated within pre match briefings as they were 'often more structured with less opportunity to contribute'. Although open debate was employed one player identified that the coach had to employ clear turn taking in order to prevent the session turning into 'chaos'. It was also evident that one player saw the open debate as an important forum to put their own views forward as they felt this could influence the coach's assessment of their performance during feedback sessions. 


\subsection{Timing of feedback: Implication for self-reflection}

The timing of feedback via PA approaches is something which to date appears to have received limited attention in coaching literature. Findings from the survey relating to the preferred timing of feedback sessions identified that most players preferred feedback either the next day (35\%) or with a 2 day (58\%) gap before receiving video feedback. These results presented in Table 2 are comparable to those reported by Francis and Jones (2014) observed in Rugby Union. A number of the interviewees voiced their opinions why delayed feedback was preferable:

\footnotetext{
Yeah I think like you should really have a think about it the next day and when you come back into training be able to watch it and maybe think differently about the game. Club C Player 1: Academy Player

No, I reckon it's perfect like you get to think over the weekend...for a couple of days on how you did and then to reassure yourself you get to watch the clips. Club C Player 2: Academy Player

I think the timing's right because it gives you time to think about what's happened over the weekend and then when you come back you're fresh-minded. Club C Player 2: Academy Player
}

However some players also made it clear that they preferred immediate video feedback. Key themes largely focused around dwelling on a poor performance or mid-week fixtures impacting on time constraints within the training week (refer to Table 6). Some players expressed a desire to complete the review process of the game immediately so they could begin to focus on the next match. McArdle et al. (2010) reported similar findings in that providing time to reflect within the debriefing environment was appropriate as this was critical in allowing player emotions to settle down. McArdle et al. (2010) identified that some team performers are still too emotionally involved with the game, thus lacking the objectivity needed to complete effective self-analysis due to their emotional state if debriefing took place too close to the performance. However preceding research also identified it was not uncommon for some coaches to utilise immediate post-competition debriefing and feedback because they believed this was the point at which the athletes 
were most honest and their recall of performance was at its clearest (McArdle et al., 2010).
No I think it's better as soon as possible to be honest then you can work on it through the week and see where you went wrong and see what you did good and see if you can improve where you went wrong. Club C Player 3: Academy Player You've got to do it sometime so you might as well do it there and then. The game's still in your
head. Club C Player 4: Academy Player

\begin{abstract}
because you're still thinking about it. Club C Player 5: Academy Player Player 5: First Team player

I think Tuesday morning is the correct time for post-match feedback, however if we have a midweek game then Monday morning would be better. Club A Player 3: First Team Player
\end{abstract}
Because you're thinking about how you've played and you just want to see it like the day after
Post-game feedback is often delivered on a Tuesday, I think it would be better if this could be done on a Monday morning then it's out of the way and I can focus on the next game. Club A

It is noteworthy to observe the contrasting opinions across players within the same squads. Although the majority prefer receiving feedback one or two days after the game, some players certainly value immediate feedback. It would appear a standard approach to a team post-match briefing might not be conducive with the potentially varied learning preferences highlighted. The use of technology could possibly facilitate a more individual approach by making video and analysis available to players straight away following a performance for the players who require more instant feedback. Using video sharing technology players could engage with any analysis in their own time in advance of team briefings which might take place later in the week. Similarly, the varied player preferences and different mind-sets towards feedback might also suggest more individual approaches to feedback and debriefing might be more conducive with learning, because they emphasise the importance of individual, small group and functional unit feedback opportunities. It is difficult to draw comparisons to some of the early motor learning research which has employed simple skill acquisition tasks and parallels to how immediate and delayed feedback is currently used within football clubs (Hodges and 
Franks, 2008). However some evidence has started to support the advantages of delayed feedback on enhancing decision-making in sports which require tactical dimensions (Raab et al., 2005; Lawrence et al., 2013). When we consider the fixture congestion potentially faced by professional players (Carling et al., 2014) we can also see the need to change focus to upcoming games as soon as possible. The need for a quick feedback turn-around is given further credibility when we consider at first team level there is an increased focus on pre-game analysis of the opposition (Wright et al., 2014).

A secondary advantage of delayed feedback is the opportunity created (intentionally or not) for players to reflect on their performance. The use of video has been suggested to support individual reflection, enabling a deeper understanding of game events, subsequently resulting in an increase in confidence and motivation (Bower et al., 2011). Francis and Jones (2014) suggested that video enables individuals to recall the whole event allowing for deeper meaningful reflection. A number of players value individual reflection stating that it helps them to 'track their progress' and remove presumptions in order to 'allow a more precise view of performance'. Another player stated that they record their own statistics 'in order to set targets to improve weaknesses'. The most common reflection episodes reported by players include: post-game team feedback; postgame individual feedback with coach, and individual self-analysis related tasks. Most players interviewed engaged in some level of self-reflection in their own time but the extent of this differs greatly, as highlighted by the player comments stated below. Most commonly clips and DVDs were provided for players to watch in their own time. In some instances players were set specific tasks to analyse aspects of their own performance, common examples included pass completion, attempts on goal, successful tackles and set piece analysis. Players on the whole commented positively on the use of video and clips 
in their own time resulting in enhanced self-reflection and learning. This often related to an understanding of individual and team spacing, positional roles and decision making in specific contexts (Table 4). Players also commented on the importance of reflecting on both strengths and weaknesses within their game.

There are a number of positive examples provided within these findings where PA could potentially be a useful mechanism in facilitating more player-centred coaching. It has been seen that by allowing players to reflect, analyse and provide commentary on their own performance, more 'power sharing approaches' (Groom et al., 2011) such as these might allow players to take responsibility for their own learning and subsequently result in a more positive learning environment (Cushion and Jones, 2006). However such player centred approaches have not been commonly exhibited within elite football academy environments (Cushion and Jones, 2006; Groom et al., 2012; Huggan et al., 2014; Partington and Cushion, 2013; Booroff et al., 2015). The approaches which are exhibited within elite football academy environments have tended to be associated with oppressive, highly authoritarian styles of coaching with a clear power imbalance being maintained and sometimes being reinforced by directive approaches employed during video feedback sessions (Groom et al., 2012). Football coaches have also previously identified their coaching knowledge as being key to developing credibility and respect (Potrac et al., 2002). It has been identified that performers on the receiving end of video sessions (ice hockey players) which were perceived to be not well organised and delivered with a lack of confidence and a 'weak presentation format' can often result in players questioning the coaches' instruction, thus resulting in a lack of respect (Nelson et al, 2011:9). Possibly football coaches might be reluctant to employ approaches which are perceived to be more undirected with more open discussions, for fear that players might perceive this as a 
weaker delivery approach. It was also identified that a 'weak delivery approach' resulted in players openly rejecting the analysis of the coach in front of the whole group (Nelson et al., 2011:9). Clearly if respect is not established in the first instance and players are not accustomed to the use and importance of self-analysis and player focused learning they might struggle to accept such non-directed approaches. There are a number of very complex issues which the coach and analyst might have to consider while attempting to devise the most effective feedback sessions. Also careful consideration has to be given when interpreting Table 1 and 2 in relation to the players' preferences to feedback. Are these findings potentially as a consequence of the traditional approach that they are accustomed to rather than a legitimate concern for their learning or improvement?

I'd rather watch the game myself and like let the likes of you do the video and the analysis and the sheets and that because I learn more from that than I would do doing it myself. Club B Player 2: Academy Player

Yes it does help a lot because when you're watching back on clips you see things that you don't see on the pitch at the time whereas things like if I'm running with the ball somebody might've made a run and I haven't seen him but when you're watching it back you're like 'oh yeah I could've passed it to him there'. And it makes you aware of things that you're not really aware of when you're on the pitch so you can improve on it. Club B Player 2: Academy Player

I think over the past year on my scholarship I have developed my learning/game understanding and this will hopefully stand me in good stead for the future. Club A Player 1: Academy Player

Yes and this is something I enjoy doing, it's a different type of learning other than on the training field. Club A Player 3: Reserve Team Player

Yes, we get individual clips and have to fill in self-reflection sheets. Club B Player 1: Academy Player

Say if we didn't have the video we wouldn't be able to reflect on how we did and what we did wrong. So it obviously helps and then it makes us improve quicker. Club B Player 5: Academy Player

Yes I'm always willing to explore new ways in which I can improve my game. Club B Player 5: Academy Player

Watching my own clips since I've been playing in a new position...I feel that I've learnt a lot more than I did by just getting coached. Club C Player 3: Academy Player

I think it's important to, I mean if you care about it you'll do it in your own time anyway but I don't think many people do. Club C Player 5: Academy Player 
Similarly a notable amount of players exhibited limitations in their ability to analyse performance themselves and found it difficult to effectively assess their performance without the aid of a coach present (refer to Table 4). Three players commented that they were much less likely to reflect and analyse their performance when they lost as opposed to when they won. Only four players valued on pitch training much more than video sessions, with the majority suggesting that video was an important supplement to their pitch training. Research has highlighted a number of challenges associated with the conditions surrounding effective reflection including: access to peers, current stages of learning and context/environmental factors (Gilbert and Trudel, 2005; Cropley et al., 2012). Clearly effective self-reflection might not be a skill that all players possess without specific training. Similarly if we consider the amount of contextual information available to players generated by $\mathrm{PA}$, it has been shown that some players might lack sufficient experiences to know what to focus their reflection on (Martindale and Collins, 2007).

\footnotetext{
The process of picking out faults or corrections is usually done by the analyst, however we have the full DVD if we want to as well. I have to admit I'm more likely to do this after a win than a loss. Club A Player 1: Academy Player

Yes we can always watch videos and clips from the game, I think it can be useful but I prefer to be out on the training pitch. Club A Player 5: Academy Player
}

The players in this study appear to value self-reflection facilitated through the use of video footage. In the study by Groom et al. (2011), coaches identified the importance of having players who are able to reflect on performance. If the aim is to develop reflective players then the recommendation is that players should be given the opportunities to help develop the skills to conduct effective self-reflection (Martindale and Collins, 2007).

Within the current literature only a handful of strong examples have provided evidence for the impact which PA has on behaviour change (Bourne, 2012 in cricket; Kuper, 2012 
in football). Clearly the players in this study identified a number of specific instances where PA directly impacted on their subsequent actions and behaviours. Some of the key examples included: PA resulting in a deeper understanding; improvement in unforced errors and enhancement in decision making. Players also identified PA impact in terms of assisting in their understanding of coaching points and providing clarification of their instructions. An important concept identified is the role of PA in creating a dialogue between the coach and player relating to specific strengths, weaknesses and ability to execute a specific game plan (Huggan et al., 2014). These aspects are recreated in a practical sense. Players commented on such opportunities as being central to their learning and development (refer to Tables 5 and 6). Although only briefly identified within this study, these factors are important in further exploring to what extent PA might impact directly on behaviour change, and thus warrants further investigation.

Yes, I think I make better decisions having watched my individual clips as I can identify regular weaknesses in my game. Club A Player 1: Academy Player

Yeah I think so say if you can tell when something's not right or when you're doing something wrong and if he tells you then you can work on it straight away can't you, in training or something. Club A Player 3: Academy Player

The differences observed depending on level is further supported by Table 7 which identifies key differences in terms of the winning orientated focus exhibited by the players from within the first team and reserve squads, while the academy players tended to illustrate the use of PA from a more developmental perspective. Clearly varied approaches to feedback could be observed (refer to Table 7), and based on these findings alone, it was not possible to establish the preferred approach or ways of working of the coach and how this might differ between senior first team and academy environments. Despite this, previous research had supported that the coach's delivery philosophy was influenced by how they viewed the role as either being associated with winning or 
developing players (Groom et al., 2011; Booroff et al., 2015). Although only a fairly modest sample was provided from three clubs it did provide some support for Groom et al. (2011) findings that PA approach might differ from a first team to an academy environment and these aspects should be further explored within future research.

\subsection{Conclusion}

Although this study is in agreement with previous findings on the importance of individual player learning preferences and approaches, the present data has further developed important aspects which are consistent in relation to the use of PA across clubs and standards of play which impact on player engagement with PA approaches. The dissemination of PA information most commonly came via group / team feedback sessions, one to one individual feedback and player reviews. There was also evidence of unit feedback (functional unit group i.e. group of defender or strikers) and player led analysis tasks. Clearly approaches to dissemination of PA generated feedback differ greatly amongst coaches from an approach which is highly coach centred and which directs all information provided, to one which facilitates open discussion and debate during feedback sessions. In general a strong theme emerged as players commented positively in regards to feedback sessions when they were asked questions and given the opportunity to engage in discussion. They felt that this resulted in a greater impact on their learning, game understanding, individual development and identification of strengths and weaknesses. Players also commented positively in terms of the importance of PA feedback opportunities providing them with an opportunity to analyse their own performance (refer to Table 4). Again players tended to be of a consensus that individual clips were most useful in terms of their own personal development in allowing them to 
assess their performance against set objectives. Notably, however, players still saw the value of watching a full game and receiving game statistics in certain situations. Some players identified that PA played a central role in their own personal reflection on their performance, but a handful of players commented on their inability to effectively selfreflect without the aid of the coaching staff. A number of other factors relating to the psychological considerations of PA were identified. These could be attributed to the differences in PA usage at first team and academy level but were not explored due to the scope of the present study. These aspects have not been considered elsewhere and might warrant further investigation.

Although some common themes have been suggested across clubs and standards of play, the overriding conclusion of this study has been that a 'one size fits all' approach to PA is flawed. Not only should preferred learning approaches and preferences of the players be a central consideration in planning effective PA approaches (cf. Groom and Cushion 2005), but also the manner in which PA approaches are formed and delivered will be central to their impact. A key factor in this is the coach's awareness of their own delivery approaches and delivery preferences. Due to the scope of this study, no consideration was given to the implications of specific playing position in the responses which players provided. Possible future research might want to consider if there are specific preferences exhibited amongst specific positions. With the diversity of nationalities within the top tiers of football it might be of interest to consider the possible perceptions of none 'home grown' players. 


\subsection{Some important lessons: Impact on players}

In addressing the key aim of this section: Identify player perceptions of PA use within football environments, the following key themes emerged: the level of debate between player and coach during debriefing sessions; the use of PA technology and approach to facilitate self-reflection; and the impact of player preference impact on the time of feedback and their engagement with self-analysis.

The level of debate seemed to vary across clubs, with some players identifying positive accounts of open discussion around performance and others reporting more directive delivery of instructional information (refer to Table 3). Although it has been discussed that open debate might be seen as being conducive with developing athlete-centred learning and subsequently enhancing learning this could potentially be a major challenge for a coach to create an appropriate environment to facilitate such approaches. Potentially the skills required to facilitate such sessions might be beyond the current ability of some coaches who don't feel comfortable standing in front of a group and managing difficult discussions and questions around performance. Clearly some players are still exposed to a more directive and instructional experience during their feedback sessions. Although not explored within the scope of this current study it might be important to consider if players have the confidence, aptitude and willingness to engage with more open and discursive feedback approaches especially when players may have only ever been required to engage passively during previous feedback sessions.

Possibly a balance to such approaches has to be established, where more directed team post-match briefings might be supplemented with more open discussion, player led activities and discussions within functional units and or individual feedback environments. 
The use of video and clips being made available to players was key in facilitating selflearning and reflection within the players own time, thus increasing their opportunity for independence and self-learning. However it appeared some players were not able to conduct their own analysis and found it difficult to critically analyse performance. This suggested that simply having the information available is not necessarily sufficient to facilitate effective self-reflection on behalf of the player. Some players clearly need further guidance and support in what to look for and why. Players also commented on the importance of self-reflection being more closely linked to performance expectations i.e. role requirements, team shape; clear coach expectation (refer to Table 4).

A number of factors have indirectly related to learning preferences and approaches. The most obvious example of this was some players have the need to analyse and reflect immediately following performance. In contrast, other players felt too emotionally close to the game, thus need more time before they could effectively and objectively reflect on performance (refer to Table 6). The potential of PA related technologies would possibly provide a more flexible solution to these varied player requirements i.e. the full game or clips could be made available for all players to watch immediately after the game in their own time if they felt necessary, in advance of any team post-match review at the club. As a result players who wish to review performance immediately are able to, while players with other preferences can chose not to. 


\subsection{References}

Abraham, A., and Collins, D. (2011). Effective skill development-how should athletes' skills be developed. In D. Collins, A. Button and H. Richards (Eds.), Performance psychology: a practitioner's guide. pp. 207-230 . Oxford, England: Elsevier.

Allen, J. B., and Hodge, K. (2006). Fostering a learning environment: Coaches and the Motivational climate. International Journal of Sports Science and Coaching, 1(3), 261277.

Alvarez, G. and Cavanagh, P. (2004) The capacity of visual short-term memory is set both by visual information load and by number of objects, Psychological Science, $15,2,106-111$.

Athens, L. H. (1984) Scientific criteria for evaluating qualitative studies. Studies in Symbolic Interaction, 5, 259-268.

Booroff, M., Nelson, L. and Potrac, P. (2015). A coach's political use of video-based feedback: a case study in elite-level academy soccer. Journal of Sports Sciences. 34,2,116-124.

Bourne, M. (2012).The role of Performance analysis within ECB. Sports Analytic Conference: The Sports Office November 2012. Manchester University Business School. Accessed on 16/02/2012. Available online at: http://www.youtube.com/watch?v=b91_VB7bPMg

Bower, M., Cavanagh, M., Moloney, R. and Dao, M. (2011) Developing communication competence using an online Video Reflection system: pre-service teachers' experiences. Asia-Pacific Journal of Teacher Education, 39, 4, 311-326.

Bunce, D. M., Flens, E. A. and Neiles, K. Y. (2010) How long can students pay attention in class? A study of student attention decline using clickers. Journal of Chemical Education, 87, 12, 1438-1443.

Casebeer, A,L. and Verhoef, M,J. (1997). Combining qualitative and quantitative research methods: considering the possibilities for enhancing the study of chronic diseases. Chronic Disease Canada. 18 (3), 130-5.

Cassidy, T., Jones, R.L. and Potrac, P. (2004). Understanding Sports Coaching: The Social, Cultural and Pedagogical Foundations of Coaching Practice, Routledge, London.

Cassidy, T., Stanley, S. and Bartlett, R. (2006). Reflecting on Video Feedback as a Tool for Learning Skilled Movement. International Journal of Sports Science and Coaching, (1), 3, 279-288.

Carling, C., Wright, C., Nelson, L. and Bradley. P. (2014) Comment on 'Performance analysis in football: A critical review and implications for future research'. Journal of 
Sports Sciences, 32, (1), 1-7

Collins, D. (2012). Useful Tool of Swiss Army Knife. Sports Analytic Conference: The Sports Office November 2012. Manchester University Business School. Accessed on 16/02/2012. Available online at:

http://www.youtube.com/watch?v=CipqiigPw40

Corbin, J. and Strauss, A. (2008). Basics of Qualitative Research: Techniques and procedures for developing grounded theory. Los Angeles, CA: Sage.

Cropley, B., Miles, A. and Peel, J. (2012). Reflective Practice: Value of, Issues, and Development within Sports Coaching. Sports Coach UK Research Project (Mach 2012). Accessed 15/07/15. Available online at: http://www.sportscoachuk.org/sites/default/files/Reflective-Practice-Report 0.pdf

Cruickshank, A., Collins, D. and Minten, S. (2013). Culture Change in a Professional Sports Team: Shaping Environment Contexts and Regulating Power. International Journal of Sports Science and Coaching, 8,(2), 271-290.

Cruickshank, A., Collins, D. and Minten, S. (2014). Driving and Sustaining Culture Change in Olympic Sport Performance Teams: A Frist Exploration and Grounded Theory. Journal of Sport and Exercise Psychology, 36, 107-120.

Curzon-Hobson, A., Thomson, R. W. and Turner, N. (2003). Coaching a critical stance. Journal of Philosophy of Sport, 30(1), 68-83.

Denison, J. (2010). Planning, practice and performance: The discursive formation coaches' knowledge. Sport, Education and Society, 15(4) 461-478.

Francis, J. and Jones, G. (2014) Elite Rugby Union Players Perceptions of Performance Analysis. International Journal of Performance Analysis in Sport, 14, 188207.

Gilbert, W. and Trudel, P. (2005). Learning to coach through experience: Conditions that influence reflection. Physical Educator, 62, 32-44.

Glaser. B,G. and Strauss, A,L. (2012). The discovery of Grounded Theory: strategies for qualitative research. Aldine Transaction: London.

Glazier, P.S. (2010). Game, set and match? Substantive issues and future directions in performance analysis. Sports Medicine. 40, 625-634.

Grecic, D. and Collins, D. (2013). The epistemological chain: practical applications in sports. QUEST, 65, 2, 151-168.

Groom, R. and Cushion, C. (2005). Using of Video Based Coaching With Players: A Case Study. International Journal of Performance Analysis in Sport, 5, 3, 40-46.

Groom, R., Cushion, C. J. and Nelson, L. J. (2011). The delivery of video-based 
performance analysis by England youth football coaches: towards a grounded theory. Journal of Applied Sport Psychology. 23, 16 - 32.

Groom, R., Cushion, C. J. and Nelson, L. J. (2012). Analysing coach-athlete 'talking in interaction' within the delivery of video-based performance feedback in elite youth soccer. Qualitative Research in Sport, Exercise and Health. 4,3,439-458.

Giacobbi, P., Poczwardowski, A. and Hager, P. (2005). A pragmatic research philosophy for applied sport psychology. The Sport Psychologist, 19, 18-31. Exercise Psychology, 17, 1-17.

Gutkind, L. (1997). The art of creative nonfiction: Writing and selling the literature of reality. New York: Wiley.

Harvey, S., Cushion, C. and Massa-Gonzalez, A. (2010). Learning a new method: teaching games for understanding in the coaches' eyes. Physical Education Sport Pedagogy. 15 (4): 361-382.

Harwood, C., Drew, A. and Knight, C. (2010). Parental stressors in professional youth football academies: A qualitative investigation of specialising stage parents. Qualitative Research in Sport, Exercise and Health, 2: 39-55.

Hodges, N.J. and Franks, I.M. The provision of Information (2008). In M. Hughes and Franks (Eds.), The essentials of Performance Analysis An Introduction. London: Routledge, 21-39.

Huggan, R., Nelson, L. and Potrac, P. (2015). Developing micropolitical literacy in professional soccer: a performance analyst's tale. Qualitative Research in Sport Exercise and Health. 7,4,504-520.

Jones, R. L. (2000) Toward a sociology of coaching. In: Jones, R.L. and Armour, framework for social analysis, Quest, 54, 34-48.

Jones, R. L., Armour, K. M. and Potrac, P. (2002). Understanding the coaching process: a K.M. (Eds.) The sociology of sport: theory and practice. Addison Wesley Longman, London.

Jones, R.L. and Wallace, M. (2005). Another bad day at the training ground: Coping with ambiguity in the coaching context. Sport, Education and Society, 10(1), 119134.

Keegan, R.J, Harwood, C. G., Spray, C.M., and Lavallee, D. (2009). A qualitative investigation exploring the motivational climate in early career sports participants: coach, parent and peer influences on sport motivation. Psychology of Sport and Exercise, 10 (2009), 361-372

Keegan, R.J., Spray, C.M., Harwood, C.G., and Lavallee, D. (2014). A qualitative 
investigation of the motivational climate in elite sport. Psychology of Sport and Exercise, 15 (2014), 97-107.

Kuper, S. (2012). Football Analytics: The Money Ball of Football, an outsiders perspective. Sports Analytic Conference: The Sports Office November 2012. Manchester University Business School. Accessed on 16/02/2012. Available online at: http://www.youtube.com/watch?v=YaTALIjKvAQ

Lawrence, G., Kingston, K. and Gottwaid, V. (2013) Skill acquisition for coaches (pp. 30-45). In: Jones, R. and Kingston, K. (Eds.) An introduction to sports coaching: Connecting theory to practice. Routledge, Abingdon

Lincoln, Y. S., \& Guba, E. G. (1986). Naturalistic inquiry. Beverly Hills, CA: Sage.

Lincoln, Y., Lynham, S. and Guba, E. (2011). Paradigmatic controversies, contradictions, and emerging confluences, revisited. In N.Denzin and Y. Lincoln (Eds.), The SAGE Handbook of Qualitative Research. (4th ed.) (pp 97-128), London: Sage

MacNamara, A., Button, A. and Collins, D. (2010). The role of psychological characteristics in facilitating the pathway to elite performance Part 1: Identifying mental skills and behaviours. The Sport Psychologist, 24,52-73.

Mackenzie, R. and Cushion, C. (2012).Performance analysis in football: A critical review and implications for future research. Journal of Sports Sciences, 31, 63976.

Martindale, R. and Nash, C. (2013). Sports science relevance and application: Perceptions of UK coaches. Journal of Sports Sciences, 31,8,807-819.

Martindale, A. and Collins, D. (2007). Enhancing the evaluation of effectiveness with professional judgement and decision making. The Sports Psychologist, 9, 458-474.

McArdle, S., Martin, D., Lennon, A. and Moore., P. (2010). Exploring debriefing in sports: a qualitative perspective. Journal of Applied Sport Psychology. 22:3, 320-332.

Niglas, K. (2000). Combining quantitative and qualitative approaches: European Conference of Educational Research, Edinburgh. Education-Line.

Nelson, L., Potrac, P., and Groom, R. (2011). Receiving video-based feedback in elite ice-hockey: a player's perspective. Sport, Education and Society.1-22,iFrist.

O’Donoghue, P.G. (2010). Research methods for sports performance analysis. Routledge: London

Ollis, S., and Sproule, J. (2007). Constructivist coaching and expertise development as action research. International Journal of Sports Science and Coaching, 2(1), 1-14. 
Pain, M.A. and Harwood, C.G. (2004). Knowledge and perceptions of sports psychology within English soccer. Journal of Sports Sciences, 22,813-826.

Partington, M. and Cushion, C. (2013). An investigation of the practice activities and coaching behaviour of professional top-level youth soccer coaches. Scandinavian Journal of Medicine and Science in Sports, 23, 372-382.

Potrac, P., Brewer, C. and Jones, R. L. (2000). Toward a holistic understanding of the coaching process. Quest, 52, 186-199.

Potrac, P., Jones, R. L. and Amour, K. A. (2002) It's all about getting respect: the coaching behaviours of an expert English soccer coach. Sport, Education and Society. 7, 183202.

Raab, M., Masters, R. and Maxwell, J. (2005). Improving the 'how' and 'what' decisions of elite table tennis players. Human Movement Science, 24, 3, 326-344.

Rasmussen, L. (2015). Learning Styles Are appealing But Misleading: Global Cognition. Accessed 15/07/15. Available online at:

http://www.globalcognition.org/head-smart/learning-styles-appealing-misleading/

Reeves, M.J. and Roberts, S.J. (2013) Perceptions of Performance Analysis in Elite Youth Football. International Journal of Performance Analysis in Sport, 13, 200-211.

Reilly, T. P. and Williams, A. M. (2005). Preparation and training for soccer. Journal of Sports Sciences, 23(6), 559-658.

Shenton, A,K. (2004). Strategies for ensuring trustworthiness in qualitative research project. Education for Information. 22, 63-75.

Smith, M,F. (2010). Research Methods in Sport. Learning Matters: Exeter.

Smith, B. and Sparkes, A. (2005) Men, sport, spinal cord injury, and narratives of hope. Social Science and Medicine. 61, 1095-1105.

Sparkes, A. and Smith, B. (2014). Qualitative Research Methods in Sport, Exercise and Health: from process to product. Routledge:Oxon.

Stringer, E.T. (2007). Action Research ( $3^{\text {rd }}$ ed.). Thousand Oaks, CA: Sage.

Williams, A,M. and Hodges N. (2005). Practice, Instruction and skill acquisition in soccer: challenging tradition. Journal Sports Sciences, 23 (6): 637-650.

Wright, C; Atkins, S; Jones, B. (2012). An analysis of elite coaches' engagement with performance analysis services (match, notational analysis and technique analysis). International Journal of Performance Analysis of Sport, (16), 436-451. 
Wright, C; Atkins, S; Jones, B, Todd, J. (2013).The role of an elite match analysts within football. International Journal of Performance Analysis, 22, 240-261.

Wright, C., Collins, D., Carling, C. (2014). The wider context of performance analysis and it application in the football coaching process. International Journal of Performance Analysis of Sport, 14, (3), 709-733

Youth Development Rules. (2012). The Premier League: The Elite Player Performance Plan (EPPP). Accessed 15/07/15. Available online at: Downloads/youthdevelopment-rules.pdf 
Table 3: Delivery of feedback of PA information to players, perceived positive and negative aspects

\begin{tabular}{|c|c|c|}
\hline $\begin{array}{l}\text { General } \\
\text { Dimension }\end{array}$ & Higher Order Themes & Lower Themes \\
\hline \multirow[t]{3}{*}{$\begin{array}{l}\text { Positive: } \\
\text { Discussion }\end{array}$} & $\begin{array}{l}\text { Player contribution and } \\
\text { interaction }\end{array}$ & $\begin{array}{l}\text { Coach is always open to discussion } \\
\text { If players are not engaged during feedback it is not } \\
\text { effective } \\
\text { Important players put their side across } \\
\text { Debate is healthy } \\
\text { Players must give as much as the manager otherwise it } \\
\text { does not work } \\
\text { Coach asks questions how players could improve } \\
\text { The player's point of view is important, it might affect } \\
\text { what the coach says }\end{array}$ \\
\hline & $\begin{array}{l}\text { Player must feel comfortable } \\
\text { sharing opinion within the } \\
\text { group }\end{array}$ & $\begin{array}{l}\text { All players should contribute } \\
\text { Provides a different perspective on the game } \\
\text { Enhances shared team understanding } \\
\text { Players voice their opinions in a non-confrontational } \\
\text { manner }\end{array}$ \\
\hline & $\begin{array}{l}\text { Team briefings are packed } \\
\text { with discussion }\end{array}$ & $\begin{array}{l}\text { Group discussions have a positive effect on team spirit } \\
\text { Given opportunity to answer questions in group and } \\
\text { individual setting } \\
\text { Group interaction enhances learning } \\
\text { Players learn more via questioning }\end{array}$ \\
\hline $\begin{array}{l}\text { Mixed } \\
\text { consideration } \\
\text { open debate }\end{array}$ & Limitations & $\begin{array}{l}\text { Feedback sessions are very much open, } \\
\text { Pre-match opposition presentations are often more } \\
\text { structured with less opportunity to contribute } \\
\text { Team feedback sessions are very open } \\
\text { Individual clips don't have specific sessions set aside to } \\
\text { discuss with the manager } \\
\text { Players require permission to make a point to avoid chaos } \\
\text { Players feel they can influence the coaches to see it from } \\
\text { their perspective. }\end{array}$ \\
\hline $\begin{array}{l}\text { Negative: } \\
\text { Discussion }\end{array}$ & $\begin{array}{l}\text { No discussion and interaction } \\
\text { during the sessions }\end{array}$ & $\begin{array}{l}\text { Just listen and take in, no engagement } \\
\text { No opportunity to voice opinion } \\
\text { If player gives their opinion its often disagreed with } \\
\text { One way communication } \\
\text { Staff direct all information / instructions } \\
\text { Focus on positive and negative aspects of performance }\end{array}$ \\
\hline $\begin{array}{l}\text { Structure of } \\
\text { feedback } \\
\text { session }\end{array}$ & $\begin{array}{l}\text { Sessions are structured to } \\
\text { promote discussion }\end{array}$ & $\begin{array}{l}\text { Coach tries to encourage players to see what they did } \\
\text { well } \\
\text { Discussion is often centred around areas of weakness } \\
\text { Pre -match feedback sessions can differ in structure from } \\
\text { post-match } \\
\text { Limited opportunity to contribute during pre-match } \\
\text { feedback }\end{array}$ \\
\hline
\end{tabular}


Table 4: Perceived impact of individual feedback opportunities and implications for selfanalysis / reflection

\begin{tabular}{|c|c|c|}
\hline $\begin{array}{l}\text { General } \\
\text { Dimension }\end{array}$ & Higher Order Themes & Lower Themes \\
\hline \multirow{3}{*}{$\begin{array}{l}\text { Use of } \\
\text { Individual } \\
\text { clips }\end{array}$} & $\begin{array}{l}\text { Preference towards } \\
\text { individual clips }\end{array}$ & $\begin{array}{l}\text { Access to computers and footage to use it to its maximum } \\
\text { Provides an indicator of personal development } \\
\text { Increases self-awareness } \\
\text { Players often miss or forget important aspects from the match } \\
\text { Watching clips allows you to learn from mistakes. } \\
\text { Review important aspects of the game } \\
\text { Enhance evaluation of decision making }\end{array}$ \\
\hline & $\begin{array}{l}\text { Viewing of individual } \\
\text { clips }\end{array}$ & $\begin{array}{l}\text { In a team we discuss, but left to look at individual clips on our } \\
\text { own } \\
\text { More useful if with manager/ coach to feedback on } \\
\text { performance } \\
\text { Sometimes discuss performance with coach on a one to one } \\
\text { basis. } \\
\text { Prefer to go through it with coach. }\end{array}$ \\
\hline & $\begin{array}{l}\text { Use of clips, whole } \\
\text { game and statistics }\end{array}$ & $\begin{array}{l}\text { Players completed self-reflection sheet } \\
\text { Allows players to compare against weekly training objectives } \\
\text { and individual role objectives. } \\
\text { Analyse performance against individual positions/what coach } \\
\text { wants } \\
\text { Analyse performance against individual strengths and } \\
\text { weakness } \\
\text { Awareness of personal strengths and weaknesses } \\
\text { Performance should be analysed against the game plan more } \\
\text { Analyse performance against my opposite number } \\
\text { Analyse performance against what manager asks for } \\
\text { Look at what coach wants to improve }\end{array}$ \\
\hline \multirow[t]{4}{*}{$\begin{array}{l}\text { Assessment } \\
\text { of } \\
\text { performance }\end{array}$} & $\begin{array}{l}\text { Role in games } \\
\text { understanding }\end{array}$ & $\begin{array}{l}\text { Enhance role clarity / positional understanding and team shape } \\
\text { Develop ability to interpret and read the game } \\
\text { Training reinforces analysis work } \\
\text { Assess: pass completion, shots on target, how many goals, } \\
\text { through balls, switch play, blocked shots, set pieces }\end{array}$ \\
\hline & $\begin{array}{l}\text { Completion of } \\
\text { individual analysis }\end{array}$ & $\begin{array}{l}\text { Amount of individual analysis is dependent on available time } \\
\text { Preference to be out on the pitch } \\
\text { More likely to analyse performance after a win }\end{array}$ \\
\hline & $\begin{array}{l}\text { Different learning } \\
\text { environment }\end{array}$ & $\begin{array}{l}\text { Enjoy the variation from pitch sessions } \\
\text { Prefer to be out on the pitch }\end{array}$ \\
\hline & $\begin{array}{l}\text { Difficulties analysing } \\
\text { individual performance }\end{array}$ & $\begin{array}{l}\text { Find it difficult to analyse performance } \\
\text { Need help of the coach / analyst to do this } \\
\text { Rather analysts do all the statistics sheets and analyse, I learn } \\
\text { more that way. } \\
\text { Watch clips with fellow team mates in own time often useful to } \\
\text { get a different perspective on each other's performance }\end{array}$ \\
\hline
\end{tabular}


Table 5: Preference for team vs. individual feedback approaches

\begin{tabular}{|c|c|c|}
\hline $\begin{array}{l}\text { General } \\
\text { Dimension }\end{array}$ & $\begin{array}{l}\text { Higher Order } \\
\text { Themes }\end{array}$ & Lower Themes \\
\hline \multirow{4}{*}{$\begin{array}{l}\text { Improvements: } \\
\text { Team and } \\
\text { Individual } \\
\text { feedback }\end{array}$} & $\begin{array}{l}\text { Preference one on } \\
\text { one / small group } \\
\text { session }\end{array}$ & $\begin{array}{l}\text { Individual sessions more relevant } \\
\text { Helps achieve my personal goals } \\
\text { Good to sit down with manager, Identify on good and bad } \\
\text { Coach highlights positives, it gives a bit of a high } \\
\text { Team video feedback sessions are a little long }\end{array}$ \\
\hline & $\begin{array}{l}\text { Value of watching } \\
\text { the whole game }\end{array}$ & $\begin{array}{l}\text { Lack of relevance to most people in the session } \\
\text { Pointless watching the whole game, does not apply to me } \\
\text { Only see one or two bits which are relevant to you } \\
\text { Don't have time in current schedule, fixture crowding } \\
\text { Would not want to watch the whole game } \\
\text { Can take a DVD but I don't bother, I find it too long and boring. }\end{array}$ \\
\hline & $\begin{array}{l}\text { Amount of analysis } \\
\text { dedicated to } \\
\text { opposition }\end{array}$ & $\begin{array}{l}\text { Prefer to focus on our own game } \\
\text { Opposition's analysis only has short term impact } \\
\text { Sometimes opposition's analysis is too much, prefer to focus on } \\
\text { own game. } \\
\text { Don't get enough analysis on our game and the opposition. } \\
\text { Learn better out on the pitch } \\
\text { Opposition's analysis is too much }\end{array}$ \\
\hline & $\begin{array}{l}\text { Ownership of } \\
\text { analysis }\end{array}$ & $\begin{array}{l}\text { Analysis is for the benefit of the coach } \\
\text { Players get no statistics, unlike the coach staff }\end{array}$ \\
\hline \multirow{3}{*}{$\begin{array}{l}\text { Positives: Use } \\
\text { of individual } \\
\text { and team } \\
\text { analysis }\end{array}$} & $\begin{array}{l}\text { Identify mistakes in } \\
\text { game }\end{array}$ & Impact on context of training activities \\
\hline & $\begin{array}{l}\text { Prefer individual } \\
\text { clips }\end{array}$ & $\begin{array}{l}\text { Players also understand the importance of seeing the whole } \\
\text { game. }\end{array}$ \\
\hline & $\begin{array}{l}\text { Feedback sessions } \\
\text { give clearer } \\
\text { understanding of } \\
\text { expectations }\end{array}$ & Provides clarity to what coach is telling us \\
\hline
\end{tabular}



